\title{
Biochemical changes within a multiple sclerosis plaque in vivo
}

T A D Cadoux-Hudson, A Kermode, B Rajagopalan, D Taylor, A J Thompson, I E C Ormerod, W I McDonald, G K Radda

\begin{abstract}
Magnetic resonance spectroscopy (MRS) was performed on a superficial part of the brain containing a large multiple sclerosis (MS) lesion. Reduced levels of phosphocreatine (PCr) relative to adenosine triphosphate (ATP) were found suggesting an abnormality in energy metabolism, with an increase in the phosphodiester (PDE) peak. A follow up study 16 months later revealed reduction in size of the lesion on MRI and normal intracellular biochemistry by MRS. Four MS patients without visible superficial cerebral lesions showed no significant changes in phosphorus metabolism.
\end{abstract}

The metabolic changes accompanying the development of the multiple sclerosis (MS) lesion are poorly understood. Magnetic resonance spectroscopy (MRS) permits the study of intracellular metabolism without disturbing normal homeostasis. ${ }^{31}$ PMRS gives direct information on high energy phosphate and phospholipid metabolism.

The relative concentrations of phosphocreatine (PCr), adenosine triphosphate (ATP) and inorganic phosphate $(\mathrm{Pi})$ can be measured. In addition intracellular $\mathrm{pH}$ can also be estimated. ${ }^{2}$ Compounds in the synthetic pathway of phospholipid, such as phosphoethanolamine (PE) and phosphocholine (PC), contribute to the phosphomonoester (PME) peak. ${ }^{3}$ In the brain and liver there is a large phosphodiester peak which is formed by multiple resonances from phospholipid bilayers. ${ }^{4}$

The application of MRS to the study of human disease requires accurate localisation of the signal from the region of interest, ideally sampling progressively from surrounding tissue into the region of interest. This approach would allow comparison of biochemical changes within the same subject. The phase modulated rotating frame imaging (PMRFI) technique receives signal from a cylinder of brain tissue $(6.5 \mathrm{~cm}$ diameter and $6 \mathrm{~cm}$ deep). This volume is effectively resolved down to a series of planar discs $(6.5 \mathrm{~cm}$ diameter, $0.5 \mathrm{~cm}$ deep), resulting in an approximate volume of
$15 \mathrm{~cm}, 3$ with a $20 \%$ increase in diameter at a depth of $5 \mathrm{~cm} .^{6}$

We have used phase modulated rotating frame imaging to investigate the biochemistry of a superficial acute MS lesion and have compared it with normal appearing white matter of affected brain in MS patients and white matter in a normal control group.

\section{Methods}

PATIENTS

Five patients with clinically definite $M S^{7}$ were recruited from the National Hospital for Nervous diseases, Queen Square. Four were selected for being clinically stable and having small deep lesions (greater than $6 \mathrm{~cm}$ from skull surface) so that phase modulated rotating frame imaging (PMRFI) would receive signal from normal appearing white matter only (mean age $=33$ years, $21-43$ years). One case was selected as she had a large superficial lesion suitable for analysis with PMRFI. This patient was a 22 year old right handed woman who presented on the 12 September 1987 with gait ataxia and right optic neuritis. She had oligoclonal bands in the cerebrospinal fluid and multiple gadolinium-diethylenetriamine penta acetic acid (GdDTPA) enhancing lesions on MRI indicating current disease activity. ${ }^{8}$

A large superficial lesion ( $5 \mathrm{~cm}$ in diameter) was noted in the right hemisphere (figure) on MRI. The first magnetic resonance spectroscopy study was performed at this time. The patient subsequently satisfied the criteria for clinically definite MS. ${ }^{7}$ The patient improved clinically. Repeat MRI 16 months later showed that the original lesion was greatly reduced in size, a common finding in acute MS lesions, ${ }^{89}$ and attributable to the resolution of oedema associated with them. ${ }^{10}$ Magnetic resonance spectroscopy was repeated. Seven healthy subjects (mean age $=34$ years, 22-55 years) were studied for comparison.

\section{$M R I$ and magnetic resonance spectroscopy} (MRS)

$\mathrm{T}_{2}$-weighted MRI was performed in a Picker $0.5 \mathrm{~T}$ superconducting magnet, using a spinecho sequence $(T R=2000 \mathrm{~ms}, \mathrm{TE}=60 \mathrm{~ms}$, with $5 \mathrm{~mm}$ contiguous axial slices). 


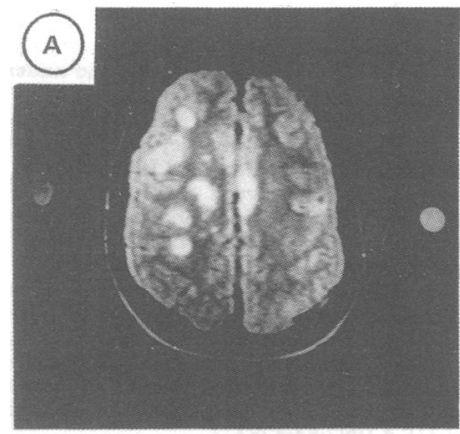

MS plaque

B Contour plot of MRS data

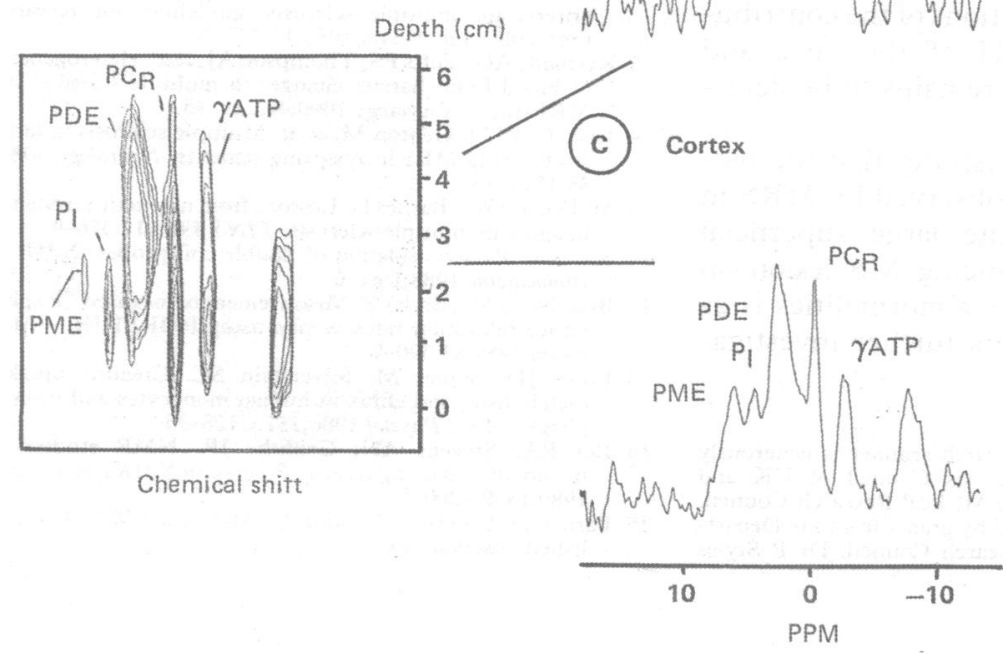

Figure Magnetic resonance imaging and spectroscopy of a multiple sclerosis plaque in vivo. The image (a) was performed (0.5T Picker) before the MRS (b). The data are presented as a contour plot (b) from which selected spectra are shown. The dots represent the proportions of the surface coil. The volume of brain studied was a cylinder perpendicular to the coil.

MRS was performed in a $60 \mathrm{~cm}$ bore $2 \mathrm{~T}$ superconducting magnet (Oxford Magnet Technology) interfaced to a Bruker Biospec spectrometer. A double surface coil, made from copper wire ( $4 \mathrm{~mm}$ thick), with separate transmitter $(15 \mathrm{~cm}$ diameter) and receiver $(6.25 \mathrm{~cm}$ diameter) coils, was tuned for phosphorus at $32 \cdot 701 \mathrm{MHz}$. The two coils were isolated from each other using a circuit described previously. ${ }^{11}$

The PMRFI pulse sequence consisted of: $\theta_{ \pm \mathrm{x}}-\lambda_{\mathrm{y}}$-acquire-relaxation delay. ${ }^{5}$ Spatial and chemical resolution were tested using a multicompartment phantom. ${ }^{6}$ A Lorentzian line fitting routine (Glinfit, Bruker) was used to measure the chemical position and area of the peaks in the phosphorus spectra at selected

Table The phosphorus metabolite levels, Mean (SEM), and pHi within normal and $M S$ controls are compared with the acute MS plaque

\begin{tabular}{|c|c|c|c|c|c|}
\hline \multirow[b]{2}{*}{$\begin{array}{l}\text { Metabolite } \\
\text { ratio }\end{array}$} & \multicolumn{2}{|l|}{ Controls } & \multicolumn{3}{|c|}{$M S$ patient with plaque } \\
\hline & $\begin{array}{l}\text { Normal } \\
(n=7)\end{array}$ & $\begin{array}{l}M S \\
(n=4)\end{array}$ & $\begin{array}{l}\text { Acute } \\
\text { lesion }\end{array}$ & $\begin{array}{l}\text { Acute } \\
N A W M\end{array}$ & $\begin{array}{l}\text { Recovery } \\
\text { lesion }\end{array}$ \\
\hline $\begin{array}{l}\mathrm{PCr} / \mathrm{ATP} \\
\mathrm{Pi} / \mathrm{ATP} \\
\mathrm{PDE} / \mathrm{ATP} \\
\text { pHi }\end{array}$ & $\begin{array}{l}1.40(0.2) \\
0.33(0.2) \\
3.70(0.3) \\
7.03(0.02)\end{array}$ & $\begin{array}{l}1.50(0.2) \\
0.37(0.1) \\
3.57(0.4) \\
7.03(0.02)\end{array}$ & $\begin{array}{l}0 \cdot 56 \\
0 \cdot 24 \\
5 \cdot 35 \\
7 \cdot 25\end{array}$ & $\begin{array}{l}0.99 \\
\text { ND } \\
3.62 \\
\text { ND }\end{array}$ & $\begin{array}{l}1.62 \\
0 \cdot 18 \\
5 \cdot 29 \\
7.02\end{array}$ \\
\hline
\end{tabular}

ND $=$ Not detected

NAWM = Normal appearing white matter. depths. Phosphocreatine/adenosine triphosphate ratios were calculated using the signal from the gamma phosphate of ATP. The spectra were not fully relaxed for some of the metabolites (phosphocreative, phosphomonoester, inorganic phosphate and possibly phosphodiester), since a repetition rate of three seconds was used. Phosphocreatine $\left(T_{1}=4 \cdot 2\right.$, normal brain) peak areas were corrected accordingly. ${ }^{12}$ Intracellular pHi measurements were made using the chemical shift between phosphocreatine and inorganic phosphate peaks. ${ }^{2}$

\section{Results}

The MRS results are presented in the table. The patients with no visible superficial lesions $(\mathrm{N}=4)$ on MRI do not differ from the normal control group $(N=7)$. The patient with the large superficial lesion had a greatly reduced phosphocreatine concentration relative to adenosine triphosphate. The $\mathrm{pH}$, as measured by the chemical shift of inorganic phosphate from phosphocreatine, is normal at the most superficial point, becoming progressively more alkaline with depth (fig). MRS of the opposite hemisphere, performed on the same day, was normal. The follow up study, 16 months later, was now normal for both hemispheres.

The superficial MS lesion was found to have a low phosphocreatine and raised phosphodiester content relative to adenosine triphosphate, and alkaline pHi. The reasons for these abnormalities from the superficial area of brain containing the MS lesion are unknown. No difference in phosphocreatine, phosphomonoester, inorganic phosphate, phosphodiester with respect to adenosine triphosphate, or $\mathrm{pHi}$ were found between normal appearing white matter in multiple sclerosis and normal controls.

Phosphocreatine and adenosine triphosphate are high energy phosphates whose levels are maintained within cells by glycolytic and oxidative phosphorylation. Adenosine triphosphate is found in all cells, but the presence of phosphocreatine in tissue requires the enzyme creatine kinase and creatine.

$\mathrm{PCr}+\mathrm{ADP}+\mathrm{H}^{+} \leftrightarrow$ Creatine $+\mathrm{ATP}$

where ADP = adenosine diphosphate

This reaction appears to be at or near equilibrium with a large equilibrium constant driving the reaction to the left. The phosphocreatine concentration varies depending on the energy state of the tissue and the total creatine content. A reduction in intracellular creatine will reduce the phosphocreatine levels relative to adenosine triphosphate. An abnormality in the creatine $/ \mathrm{Na}^{+}$pump within the lesion could cause a reduction in phosphocreatine. Though there has been no such published study of the $\mathrm{Cr} / \mathrm{Na}^{+}$pump in human neural tissue, creatine transport in human macrophages and monocytes has been shown to be $\mathrm{Na}^{+}$linked. ${ }^{13}$ Another possibility is that the energy state of the tissue within the plaque is different from normal brain due to a change in the activity of mitochondria or glycolysis enzymes. 


\section{Discussion}

The predominance of phosphodiester compared with adenosine triphosphate in the MS plaque suggests an excess phosphodiester with respect to cellular space. This may be consistent with accumulation of phospholipid bilayers ${ }^{4}$ and lipid breakdown products such as glycerophosphocholine and glycerophosphoethanolamine. ${ }^{14}$

The $\mathrm{pH}$, as measured by chemical shift of inorganic phosphate from phosphocreatine, was more alkaline within the plaque. In normal brain the majority of the $\mathrm{Pi}$ is intracellular, since the interstitial volume is small. Whether the relatively high $\mathrm{pH}$ represents a change in $\mathrm{pH}$ regulation within the cells of the lesion, or an alteration in the proportions of the contribution to overall tissue $\mathrm{pH}$ of the intra and extracellular components remains to be determined. ${ }^{15}$

This case report demonstrates that the biochemical changes can be observed by MRS in brain containing an acute large superficial Gadolinium-DTPA enhancing MS lesion on MRI. The origin of these abnormalities is as yet unknown and warrants further investigation.

The Multiple Sclerosis NMR research scanner is generously supported by the Multiple Sclerosis Council of UK an Northern Ireland, and also by the Medical Research Council. This work has also been supported by grants from the Department of Health and Medical Research Council. Dr P Styles provided invaluable help with surface coil construction and experimental design.

1 Radda GK. The use of NMR spectroscopy for the understanding of disease. Science 1986;233:640-5.

2 Taylor DJ, Bore PJ, Styles P, Gadian DG, Radda GK Bioenergetics of intact human muscle; $A$ ${ }^{31} \mathbf{P}$ nuclear magnetic resonance study. Mol Biol Med 1983;1:77-94.

3 Brenton DP, Garrod PJ, Krywawych S, Reynolds EOR, Bachelard HS, Cox DW. Phosphoethanolamine is major
constituent of the phosphomonoester peak detected by ${ }^{11} \mathrm{P}$ NMR in newborn brain. Lancet 1985;i:115-17.

4 Murphy E, Rajagopalan B, Brindle K, Radda GK. Phospholipid bilayer contribution to PDE peak in ${ }^{31} \mathrm{P}$ NMR spectra in vivo. Mag Reson in Med 1989;12:282-9.

5 Blackledge MJ, Rajagopalan B, Oberhaensli RD, Bolas NM Styles P, Radda GK. Quantitative studies of human Styles $\mathrm{P}$, Radda GK. Quantitative studies of human
cardiac metabolism by ${ }_{3} \mathrm{P}$ rotating-frame NMR. Proc Natl Acad Sci USA 1987;84:4283-7.

6 Cadoux-Hudson TAD, Blackledge $M J$, Rajagopalan B Taylor DJ, Radda GK. Human primary brain tumour metabolism in vivo: a phosphorus magnetic resonance spectroscopy study. Br J Cancer 1989;60:430-6.

7 Poser CM, Paty DW, Scheinberg L, et al. New diagnostic criteria for multiple sclerosis: guidelines for research protocols. Ann Neurol 1983;13:227-32.

8 Kermode AG, Tofts PS, Thompson AJ, et al. Heterogeneity of blood-brain barrier changes in multiple sclerosis: an MRI stuciy. Neurology 1990;40:229-35.

9 Isaac $\mathrm{C}, \mathrm{Li} \mathrm{D}$, Genton $\mathrm{M}$, et al. Multiple sclerosis: a serial study using MRI in relapsing patients. Neurology 1988; 38:1511-15.

10 McDonald WI, Barnes D. Lessons from magnetic resonance imaging in multiple sclerosis. TINS 1989;12:376-9.

11 Styles P. Passive isolation of double coil probes. NMR in Biomedicine 1988;1:61-6.

12 Blackledge MJ, Styles P. Measurement of localised ${ }^{31} \mathrm{P}$ spinlattice relaxation rates in vivo using PMRFI-IR. J Mag Reson 1989;83:390-9.

13 Loike JD, Somes M, Silverstein SC. Creatine uptake, metabolism, and efflux in human monocytes and macrophages. Am J Physiol 1986;251:C128-35.

14 Iles RA, Stevens AN, Griffiths JR. NMR studies of metabolites in living tissues. Progress in NMR spectroscopy 1989;15:49-200.

15 Barnes D, Prineas J, Landon D, McDonald WI. (Unpublished observations). 